\title{
Influência da altura das garras dos pneus de um trator em área de plantio direto
}

\author{
Antonio G abriel Filho ${ }^{1}$, Leonardo A. Monteiro², Kléber P. Lanças², Saulo P. S. G uerra ${ }^{2} \&$ Paulo R. Jesuino² \\ RESUMO
}

Desenvolveu-se este trabalho com o objetivo de se avaliar os parâmetros de desempenho de um trator agrícola equipado com um conjunto de pneus diagonais com garras altas (pneu novo) e outro conjunto de pneus diagonais de mesma dimensão, com garras mais baixas, em solo com cobertura vegetal (pal ha de milho). Utilizaram-se as velocidades teóricas de 4, 5, 6 e $7 \mathrm{~km}$ $\mathrm{h}^{-1}$, informadas no painel do trator, uma força de tração constante de $25 \mathrm{kN}$, e se mediram a força de tração, a velocidade de deslocamento, a patinagem dos rodados, o consumo horário e específico de combustível; enfim, foram calculadas a potência disponível na barra de tração e a razão entre o consumo horário e o consumo específico de combustível com a potência e 0 coeficiente de tração. Concluiu-se que, em solo com cobertura vegetal palha de milho, esses parâmetros de desempenho do trator foram semel hantes para ambas as alturas de garra dos pneus.

Palavras-chave: máquinas agrícolas, ensaio de trator, palha, carro dinamométrico, eficiência trativa

\section{Influence of tractor tire lug height in an área with no tillage}

\begin{abstract}
This work was carried out to evaluate the performance of a farm tractor fitted with two sets of tires with high lugs and another set of tires with tallow lugs in straw without tillage (corn straw). The travel speeds used were approximately 4, 5, 6 and 7 $\mathrm{km} \mathrm{h}^{-1}$ and a constant pulling force of $25 \mathrm{kN}$ was fixed. Tractor traction, forward speed, slip and consumption of fuel were measured and drawbar power, the ratio between the consumption and power and traction coefficient were calculated. It was observed that the tractor performance was similar to high and low lug tire conditions, in an area covered with corn straw.
\end{abstract}

Key words: agricultural machine, tractor test, straw, dynamometric car, tractive efficiency

${ }^{1}$ Centro de Ciências Exatas e Tecnológicas, UN IOESTE/Cascavel, PR, Fone: (45) 3220.3199. E-mail: gabriel@unioeste.br

2 Departamento de Engenharia Rural/U N ESP, Fazenda Experimental Lageado, CEP 18610-307, Botucatu, SP,CP 237 Fone: (14) 3811-7165. E-mail (s) aiveca@fca.unesp.br; kplancas@fca.unesp.br; ssguerra@fca.unesp.br 


\section{INTRODUÇÃO}

Os pneus agrícolas constituem um dos principais componentes do trator e da maioria das máquinas agrícolas, haja vista sua relevante importância nos custos operacionais de campo. Eles são o elo entre o trator e o solo, além de responsáveis por realizarem a tração que o trator irá proporcionar para arrastar as demais máquinas e os implementos agrícolas que dependem dessa sua força, para realizarem as operações no campo para as quais foram construídos.

Entre os fatores que interferem na tração, a condição da superfície do solo também é importante e, dentre as propriedades do solo que afetam a eficiência de tração de um trator agrícola, pode-se mencionar a textura do solo, a umidade desse solo e as condições da superfície, dependendo da cobertura existente sobre o solo (Yanai et al., 1999).

De acordo com Barbosa et al. (2005), os conjuntos pneumáticos do trator constituem um de seus mais importantes componentes, devido à função de se obter equilíbrio, deslocamento, direcionamento e esforço tratório.

Segundo Cordeiro (2000), a avaliação direta do desempenho de tratores em condições de campo é obtida através da instrumentação e monitoramento dos tratores, permitindo a determinação de fatores diretamente relacionados com a eficiência de trabalho do trator. O autor realizou um estudo do desempenho de um trator agrícola em função do pneu, da lastragem e da velocidade de deslocamento e concluiu que esses fatores alteraram significativamente a conversão energética, a patinagem e a força de tração.

A capacidade de um trator desenvolver a tração e fornecer potência suficiente para desempenhar a maioria das operações necessárias na agricultura depende, em parte, do tipo de dispositivo de tração. Nos casos em que esses dispositivos são pneumáticos, vários fatores interferem neste desempenho (Zoz \& Grisso, 2003), tais como: o tamanho do pneu, a pressão de inflação e as características da banda de rodagem.

Um trator equipado com pneus adequados para diferentes condições superficiais de solo, conforme os relatos de Correa et al. (1999) resulta em melhor desempenho geral com consequente aumento da capacidade operacional, aumento da vida útil, melhor qualidade de serviço, menor custo e, ainda, preserva as condições estruturais do solo.

Para exercer a tração os pneus dos tratores apresentam banda de rodagem com garras que, em contato com o solo, aumentam a eficiência desse rodado; entretanto, em áreas de Plantio Direto onde a superfície permanece firme, sem ser revolvida e com cobertura vegetal, a altura dessas garras pode não ter o efeito desejado na tração (Gabriel Filho et. al., 2004), pois elas não conseguem penetrar no solo, como ocorre quando a superfície é revolvida.

Com a adoção crescente do sistema de plantio direto aumenta a importância da escolha correta do pneu do trator. Conforme relatado por Gabriel Filho et al. (2004) na avaliação do desempenho operacional de um trator agrícola em área coberta com diferentes tipos de cobertura vegetal, a maior quantidade de matéria seca interferiu na eficiência de tração.

As condições da superfície do solo afetam também o consumo de combustível do trator. Ao avaliarem o consumo de combustível e a capacidade de campo operacional na semeadura de aveia em três manejos do solo (plantio direto, plantio convencional e escarificação), Mazetto et al. (2004) concluíram que o consumo horário de combustível e a patinagem do trator foram maiores quando a operação de semeadura foi realizada em sistema convencional e com escarificação ocorrendo, então, maior exigência de força do trator, uma vez que nesses manejos houve maior mobilização do solo quando comparado com o sistema de plantio direto.

Relacionando o consumo específico de combustível para cada equipamento, Salvador et al. (2009) concluíram que as operações de preparo do solo tais com arado, grade aradora e escarificador, proporcionaram melhor conversão energética quando utilizadas antes da subsolagem, pois menores valores de consumo especifico de combustível significam a otimização do desempenho do motor, da eficiência trativa e da adequação equipamento à fonte de potência, de forma simultânea.

Avaliando as condições da superfície do solo, Gabriel Filho et al. (2010), concluíram que esta interferiu na capacidade do trator em desenvolver a tração, pois a maioria dos parâmetros relacionados com o desempenho apresentou variações estatisticamente significativas ao longo dos ensaios.

Desenvolveu-se este trabalho com o objetivo de se avaliar o desempenho de um trator agrícola equipado com um conjunto de pneus diagonais com garras altas (pneu novo) e outro conjunto de pneus diagonais de mesmas dimensões, com garras mais baixas (pneu usado), operando em solo coberto com restos da cultura de milho e em quatro velocidades de deslocamento do trator.

\section{MATERIAL E MÉTODOS}

Os ensaios foram realizados em uma pista com $400 \mathrm{~m}$ de comprimento e $20 \mathrm{~m}$ de largura, declividade de $0,3 \%$ no sentido do comprimento e nivelada na largura, pertencente à FCA/ UNESP campus de Botucatu. As coordenadas geográficas da pista são: $22^{\circ} 51^{\prime}$ S e $48^{\circ} 25^{\prime} \mathrm{W}$ e altitude de $770 \mathrm{~m}$.

O solo da pista, de acordo com a EMBRAPA (1999), é um Nitossolo Vermelho Distroférrico com relevo plano e textura argilosa.

Para a caracterização física do solo da área experimental, realizaram-se amostragens de campo e determinações de laboratório, conforme a metodologia descrita por Khiel (1979), e EMBRAPA (1999), cujos valores obtidos se acham na Tabela 1 .

A cobertura vegetal foi oriunda dos resíduos da colheita da cultura do milho, realizada anteriormente. A semeadura do milho ocorreu em dezembro e a colheita no final do mês de abril e início de maio, com uma colhedora autopropelida marca MF 3440 sendo que, para uniformizar essa distribuição, utilizou-se um ancinho enleirador/espalhador.

O delineamento experimental adotado foi o fatorial com 2 fatores definidos em função de duas condições dos pneus e as quatro marchas escolhidas no trator. Os tratamentos foram dispostos em blocos casualizados, com três repetições, totalizando 24 unidades experimentais. 
Tabela 1. Caracterização do solo na área com cobertura vegetal

\begin{tabular}{lc}
\hline \multicolumn{1}{c}{ Característica } & Valores \\
Areia (\%) & 42 \\
Silte (\%) & 17 \\
Argila (\%) & 41 \\
Limite de liquidez (\%) & 32 \\
Limite de plasticidade (\%) & 26 \\
Densidade dos sólidos $\left(\mathrm{g} \mathrm{cm}^{-3}\right)$ & 3,10 \\
Teor de água (\%) na camada de 0 a $10 \mathrm{~cm}$ & 22 \\
Teor de água (\%) na camada de 10 a $20 \mathrm{~cm}$ & 22 \\
Índice de cone (kPa) na camada de 0 a $15 \mathrm{~cm}$ & 1.684 \\
Massa de matéria seca $\left(\mathrm{kg} \mathrm{ha}^{-1}\right)$ & 10.089 \\
\hline
\end{tabular}

O conjunto de pneus (dianteiro e traseiro) utilizado nas duas condições (novo com garra alta e usado com garra baixa) está especificado na Tabela 2.

Tabela 2. Característica dos pneus diagonais novos e desgastados utilizados nos ensaios

\begin{tabular}{llccccc}
\hline Marca & Código & $\begin{array}{c}\text { Largura } \\
(\mathbf{m m})\end{array}$ & $\begin{array}{c}\text { Diâmetro } \\
\text { extemo } \\
(\mathbf{m m})\end{array}$ & $\begin{array}{c}\text { Raio } \\
\text { estático } \\
(\mathbf{m m})\end{array}$ & $\begin{array}{c}\text { Circunferência } \\
\text { de rolamento } \\
(\mathbf{m m})\end{array}$ \\
Dianteiro & Dina Torque II & $14.9-26$ & 378 & 1316 & 615 & 3982 \\
Traseiro & Dina Torque II & $23.1-30$ & 602 & 1722 & 775 & 5106 \\
\hline
\end{tabular}

Os ensaios foram realizados com pressões de inflação dos pneus de $82,7 \mathrm{kPa}(12 \mathrm{psi})$ nos rodados traseiros e $110 \mathrm{kPa}$ (16 psi) no dianteiro, conforme recomendação do fabricante, em ambos os casos.

O primeiro conjunto de rodados, tanto traseiros quanto para os dianteiros utilizados, foi composto de pneus diagonais novos com garras no tamanho original de fabricação, denominadas garras altas; na sequência, utilizou-se o outro conjunto, de mesma dimensão e formado de pneus diagonais desgastados pelo uso, chamados garras baixas.

As garras dos pneus foram medidas segundo a ASAE (1999) utilizando-se um medidor de garra (Figura 1), em que os dados são apresentados na Tabela 3.

Todos os ensaios foram realizados com um trator marca John Deere, SLC modelo 6600, com $88 \mathrm{~kW}$ de potência no motor, operando a $2300 \mathrm{rpm}$, com tração dianteira auxiliar ligada.

No console do trator, as marchas A3, B1, B2 e C1 correspondiam à velocidade de $4,5,6 \mathrm{e} 7 \mathrm{~km} \mathrm{~h}^{-1}$, respectivamente, selecionadas por serem as mais utilizadas em operações de campo.

O trator foi pesado com todos os lastros metálicos e com $75 \%$ de água nos pneus, conforme a recomendação de lastragens metálica e líquida do fabricante; a lastragem manteve a proporção de $59 \%$ da massa do trator sobre o eixo traseiro e $41 \%$ da massa do trator sobre o eixo dianteiro. Na Tabela 4 estão os valores da massa do trator.

Para obtenção da força de tração na barra do trator utilizou-se a Unidade Móvel de Ensaio na Barra de Tração UMEB, pertencente ao NEMPA, que operou como um carro dinamométrico instrumentado, empregado na avaliação de desempenho de trator submetido a ensaio de tração. O valor
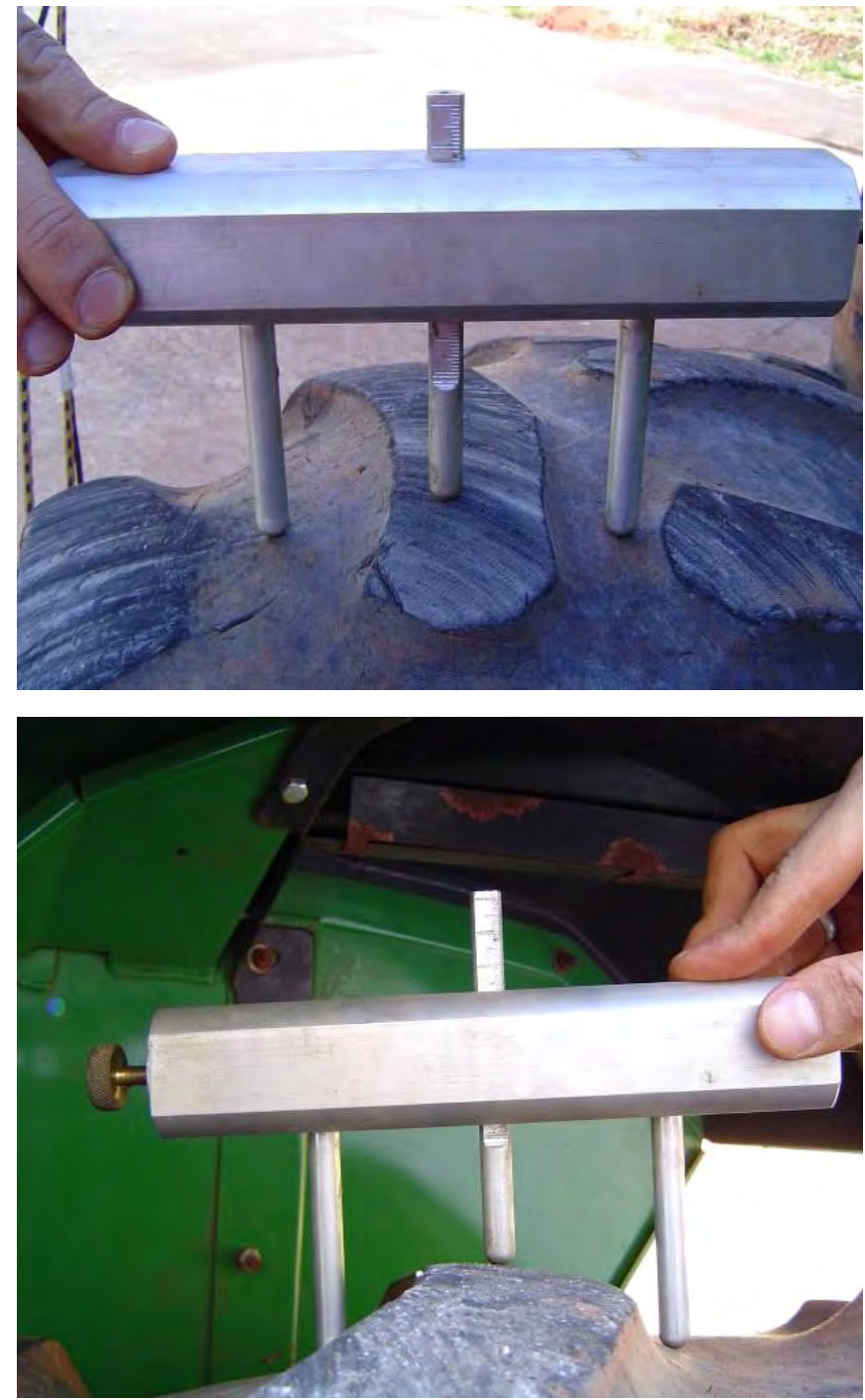

Figura 1. M edição da altura das garras dos pneus dianteiro e traseiro desgastados

Tabela 3. Dimensões da altura das garras dos pneus diagonais utilizados

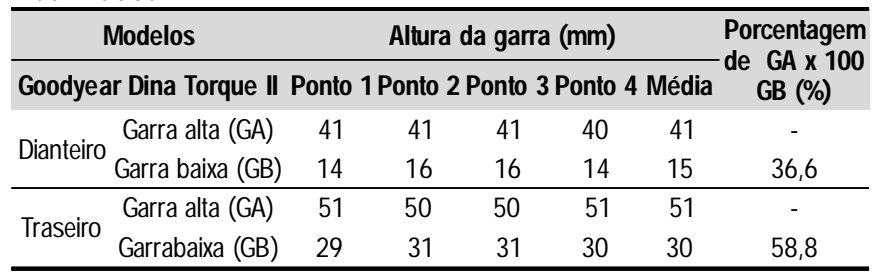

Tabela 4. Massa do trator John Deere 6600 equipado com pneus diagonais, sendo um conjunto com pneus de garras altas e outro de garras baixas

\begin{tabular}{ccccc}
\hline \multirow{2}{*}{ Rodado } & \multicolumn{2}{c}{ Garra Alta } & \multicolumn{2}{c}{ Garra Baixa } \\
\cline { 2 - 5 } & $\mathbf{( k g )}$ & $(\%)$ & $\mathbf{( k g )}$ & $(\%)$ \\
Dianteiro & 2.756 & 41 & 2.746 & 41 \\
Traseiro & 3.967 & 59 & 3.951 & 59 \\
Total & 6.723 & 100 & 6.697 & 100 \\
\hline
\end{tabular}

da força solicitada na barra de tração foi obtido através de uma célula de carga instalada no cabeçalho da UMEB. 
$\mathrm{O}$ valor de $25 \mathrm{kN}$ adotado em todos os ensaios como força de tração constante, foi ajustado e controlado através da pressão aplicada no sistema de frenagem da UMEB e monitorado por meio do indicador eletrônico de força instantânea.

Determinou-se a velocidade média de deslocamento cronometrando-se o tempo necessário para percorrer cada parcela de $25 \mathrm{~m}$ de comprimento. Colocou-se, em cada extremidade da parcela, uma baliza, a fim de permitir a cronometragem no momento exato em que o trator iniciou e terminou o percurso e os valores de velocidade foram expressos em $\mathrm{km} \mathrm{h}^{-1}$.

Os valores de velocidade e tração obtidos nos ensaios estão apresentados na Tabela 5 .

Tabela 5. Valores médios da velocidade de deslocamento e da força de tração obtidos nas quatro marchas e nas duas condições de garra dos pneus

\begin{tabular}{ccccc}
\hline \multirow{2}{*}{ Marcha } & \multicolumn{3}{c}{ Garra } \\
\cline { 2 - 5 } & \multicolumn{3}{c}{ Alta } & \multicolumn{2}{c}{ Baixa } \\
\cline { 2 - 5 } A3 & 3,4 & 24,8 & 3,5 & 25,0 \\
B1 & 3,7 & 25,2 & 3,9 & 25,1 \\
B2 & 5,2 & 25,1 & 5,3 & 25,1 \\
C1 & 5,9 & 25,0 & 6,0 & 24,9 \\
\hline
\end{tabular}

Geradores de pulso com frequência de 60 pulsos por volta, foram instalados nos rodados dianteiros e traseiros do trator. Esses geradores foram ligados, através de um cabo elétrico, ao painel indicador e ao coletor de dados instalados dentro da UMEB, onde se efetuaram as medições do número de pulso total obtido em cada parcela.

Para medição do consumo horário de combustível utilizouse um fluxômetro volumétrico com vazão de $1 \mathrm{~mL}$ - pulso. Os pulsos gerados pelo fluxômetro volumétrico foram convertidos em volume consumido por hora $\left(\mathrm{L} \mathrm{h}^{-1}\right)$.

A potência disponível na barra de tração foi calculada em função da força de tração e da velocidade de deslocamento e se calcularam, também, a razão entre a quantidade de combustível consumido, a potência disponibilizada na barra de tração e o coeficiente de tração.

Os valores obtidos nos ensaios foram submetidos a análise de variância e as médias comparadas pelo teste de Tukey a 5\% de probabilidade, enquanto a análise de regressão foi realizada para as variáveis que apresentaram análise significativa para a regressão, as quais se apresentaram em forma de figuras.

\section{RESULTADOS E DISCUSSÃO}

Os resultados do teste de significância para a variável patinagem do trator, consumo horário de combustível, potência na barra, razão entre o consumo horário de combustível a potência e o coeficiente de tração, estão apresentados na Tabela 6.

Observa-se que os tratamentos causaram variação significativa na patinagem dos rodados, no consumo horário de
Tabela 6. Valores do teste $\mathrm{F}$ da análise de variância para a patinagem do trator (Pat), consumo horário de combustível (Cons), potência na barra (Pot), razão consumo horário de combustível/potência (Rcp) e o coeficiente de tração (Coef.Tr)

\begin{tabular}{cccccc}
\hline Causa da Variação & Pat & Cons & Pot & Rcp & Coef.Tr \\
Marcha & $9,03^{*}$ & $21,74^{*}$ & $872,65^{*}$ & 1,73 & 2,02 \\
Garra & 3,00 & 0,54 & 4,19 & 0,60 & 0,65 \\
Marcha*Garra & 1,91 & 1,25 & 0,64 & 0,69 & 4,75 \\
CV & 10,46 & 11,29 & 2,14 & 11,80 & 1,38 \\
\hline
\end{tabular}

* significativo a $5 \%$ de probabilidade

combustível e na potência na barra de tração, sendo que essas variáveis sofreram alterações estatisticamente significativas, conforme foram realizadas as mudanças de marcha; todavia, não se constataram efeito das alturas das garras no desempenho do trator, de acordo com as variáveis estudadas, nem efeito da interação das quatro marchas com as duas condições de altura das garras avaliadas.

As análises do consumo horário e do coeficiente de tração apresentadas na Tabela 6 , mostram que não houve efeito significativo da altura da garra nem do aumento da velocidade para essas variáveis.

A patinagem do trator foi estatisticamente semelhante entre os pneus com alturas diferentes de garra, como pode ser observado na Tabela 7; entretanto, com as garras mais baixas a patinagem do rodado sofreu maior efeito do aumento da velocidade de deslocamento sendo estatisticamente significativa a diferença da patinagem obtida na marcha $\mathrm{A} 3$, em que a velocidade média foi de $3,5 \mathrm{~km} \mathrm{~h}^{-1}$ e marcha $\mathrm{C} 1$, com velocidade média de $6,0 \mathrm{~km} \mathrm{~h}^{-1}$. Com as garras mais altas estatisticamente, os valores médios da patinagem não se alteraram com a variação da velocidade de 3,4 até $5,9 \mathrm{~km} \mathrm{~h}^{-1}$. O aumento da velocidade tendeu a aumentar a patinagem quando o trator não dispunha de potência suficiente para atender ao aumento da demanda de potência na maior velocidade; todavia, a altura da garra interferiu nesta relação mostrando que garras maiores mantiveram a patinagem, mesmo com a elevação da velocidade de deslocamento; já os pneus com garras mais baixas aderiram melhor ao solo o que diminuiu a patinagem na menor velocidade.

Tabela 7. Valores médios da patinagem dos rodados do trator (\%) para marcha e altura das garras

\begin{tabular}{ccccc}
\hline \multirow{2}{*}{ Garra } & \multicolumn{4}{c}{ Marcha } \\
\cline { 2 - 5 } & A3 & B1 & B2 & C1 \\
Baixa & $7 \mathrm{aA}$ & $9 \mathrm{aAB}$ & $10 \mathrm{aAB}$ & $11 \mathrm{aB}$ \\
Alta & $9 \mathrm{aA}$ & $10 \mathrm{aA}$ & $10 \mathrm{aA}$ & $11 \mathrm{aA}$ \\
\hline
\end{tabular}

Médias com letras iguais, minúscula na coluna e maiúscula na linha, não apresentaram diferença significativa no teste de Tukey $(\mathrm{P}>0,05)$

Em áreas de plantio direto, onde o solo não é revolvido, as garras dos pneus conseguem penetrar muito pouco na superfície desse solo; portanto, o espaço entre garras não entra em contato com o solo diminuindo, assim, a eficiência dessas garras na tração. Os resultados apresentados por Gabriel Filho et al. (2004) relatando que a ação das garras di- 
minuiu na medida em que o solo se vai tornando mais firme, corroboram com os resultados obtidos neste trabalho.

O consumo horário de combustível foi semelhante para o trator em ambas as condições de altura de garras dos pneus, conforme observado na Figura 2. A variação do consumo foi significativa quando a velocidade de deslocamento do trator aumentou, tanto com pneus de garras baixas quanto para os pneus de garras altas.

A análise de regressão significa que o comportamento do consumo horário de combustível do trator foi linear e a equação expressa na Figura 2A representou cerca de $80 \%$ dos casos para os pneus de garra baixa e $87 \%$ nos pneus de garras mais altas.

$$
\text { A. }
$$

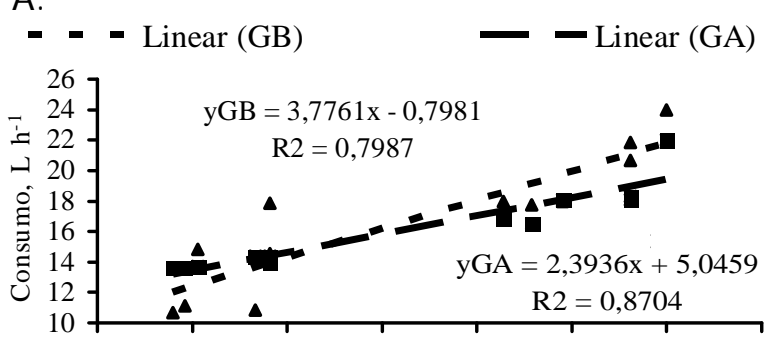

B.
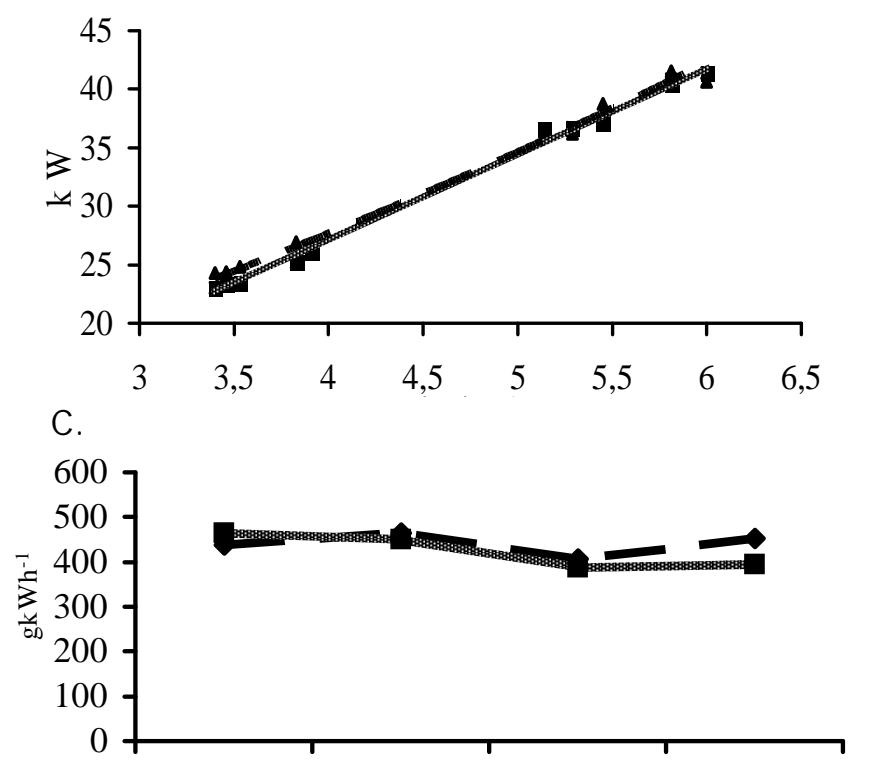

D.

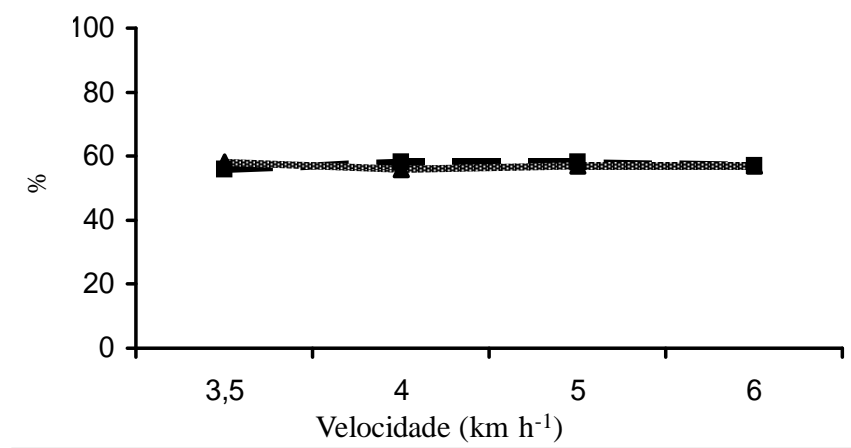

Figura 2. Valores do consumo horário de combustível em função da velocidade de deslo camento do trator com pneus de garras altas (GA) e baixas (GB), com as linhas de tendência, as equações da análise de regressão e respectivos valores de coeficiente de determinação $\left(R^{2}\right)$
Os valores médios apresentados na Tabela 8 mostram que, com a garra baixa, a diferença foi estatisticamente significativa entre os valores médios obtidos a 3,5 a $5,9 \mathrm{~km} \mathrm{~h}^{-1}$. Quando o pneu com a garra alta foi utilizado, o valor de consumo horário de combustível obtido a $3,7 \mathrm{~km} \mathrm{~h}^{-1}$ foi estatisticamente menor que aquele obtido a $5,2 \mathrm{~km} \mathrm{~h}^{-1}$ e esta, por sua vez, foi menor que a $5,9 \mathrm{~km} \mathrm{~h}^{-1}$. Esta tendência de aumento de consumo de combustível no tratamento com garras altas apresentados na Tabela 8 se deu em função da deformação do pneu no momento da tração, pneu com garra altas se deformam mais do que os pneus com garras baixas e esta deformação é energia que está sendo consumida sem gerar eficiência para a tração do trator.

Tabela 8. Valores médios do consumo horário de combustível $\left(\mathrm{L} \mathrm{h} \mathrm{h}^{-1}\right)$ para marcha e altura das garras

\begin{tabular}{ccccc}
\hline \multirow{2}{*}{ Garra } & \multicolumn{4}{c}{ Marcha } \\
\cline { 2 - 5 } & A3 & B1 & B2 & C1 \\
Baixa & $13,61 \mathrm{aA}$ & $14,24 \mathrm{aAB}$ & $17,17 \mathrm{aAB}$ & $19,47 \mathrm{aB}$ \\
Alta & $12,21 \mathrm{aA}$ & $14,42 \mathrm{aAB}$ & $17,92 \mathrm{aBC}$ & $22,17 \mathrm{aC}$ \\
\hline
\end{tabular}

* Médias com letras iguais, minúscula na coluna e maiúscula na linha, não apresentaram diferença significativa no teste de Tukey $(P>0,05)$

A variação da potência disponível na barra de tração do trator foi semelhante para ambas as alturas de garra dos pneus, o que pode ser observado na Figura 2B. O aumento da potência foi significativo sempre que a velocidade de deslocamento do trator aumentou, tanto para o trator com pneus de garras baixas como para o trator com pneus com as garras mais altas.

O aumento da potência na barra de tração em função da velocidade para uma mesma força de tração, foi linear quando o trator estava com pneus de garras altas $(\mathrm{F}=741,79) \mathrm{com}$ um coeficiente de determinação próximo de $100 \%$ e, quando o trator estava equipado com pneus de garras mais baixas, a variação quantitativa da potência na barra de tração apresentou comportamento significativo polinomial de segundo grau, em aproximadamente $99 \%$ dos casos.

Mantida a mesma força de tração, a potência aumentou significativamente, conforme a velocidade de deslocamento cresceu, como está indicado na Tabela 9.

Tabela 9. Valores médios da potência na barra de tração (kW) para marcha e altura das garras

\begin{tabular}{ccccc}
\hline \multirow{2}{*}{ Garra } & \multicolumn{5}{c}{ Marcha } \\
\cline { 2 - 5 } & A3 & B1 & B2 & C1 \\
Baixa & $24,47 \mathrm{aA}$ & $26,47 \mathrm{aB}$ & $36,97 \mathrm{aC}$ & $41,21 \mathrm{aD}$ \\
Alta & $23,28 \mathrm{aA}$ & $25,87 \mathrm{aB}$ & $36,76 \mathrm{aC}$ & $40,92 \mathrm{aD}$ \\
\hline
\end{tabular}

* Médias com letras iguais, minúscula na coluna e maiúscula na linha, não apresentaram diferença significativa no teste de Tukey $(P>0,05)$

Quando se analisou a quantidade de combustível necessária para gerar um quilowatt de potência na barra de tração, o trator apresentou, significativamente, o mesmo comportamento com pneus de garras altas ou com as garras baixas. A Figura 2C mostra os valores da razão entre o consumo específico de combustível e a potência, embora não tenha havido 
diferença estatística significativa na análise de variância dos valores obtidos nem na análise de regressão.

A razão consumo específico de combustível por potência se manteve estatisticamente constante, mesmo quando a velocidade de deslocamento do trator foi aumentada.

Para a avaliação do consumo específico de combustível, mediu-se a temperatura do combustível na entrada e saída do motor, que variou de 28 a $38^{\circ} \mathrm{C}$. a variação da temperatura e da densidade do combustível, nessa faixa de temperatura, foi inferior a $0,2 \%$ e, portanto a densidade foi considerada constante no ensaio.

A capacidade do trator em aumentar a tração aproveitando a transferência de peso para o rodado traseiro, não variou significativamente entre os tratamentos adotados neste trabalho, como pode ser observado na Figura 2D.

Em áreas de plantio direto, nas quais as condições de superfície do solo são mantidas sem alterações significativas na sua estrutura, o uso de pneus com garras mais altas não proporcionou melhoria no desempenho do trator mostrando que, neste caso, as garras poderiam ser menores $(58,8 \%$ do original na traseira e $36,6 \%$ na dianteira) sem perda significativa do desempenho do trator, concordando com dados semelhantes obtidos por Correa et al. (1999), Mazetto et al. (2004), Zoz \& Grisso (2003) e Gabriel Filho et al. (2004).

\section{CONCLUSÕES}

1. O desempenho do trator agrícola avaliado através da patinagem, do consumo horário e específico de combustível, da potência na barra de tração, da razão entre esses dois e o coeficiente de tração, foi semelhante em solo coberto com restos da cultura de milho, tanto para os pneus de garras altas (novo), quanto com pneus de garras mais baixas (usado).

2. As garras maiores mantiveram a patinagem do trator, mesmo com a elevação da velocidade de deslocamento.

3.Os pneus com garras mais baixas parecem ter aderido melhor ao solo o que diminuiu a patinagem na menor velocidade.

4.Em áreas de plantio direto, em que normalmente, o solo está coberto com restos de cultura, pneus de garra baixa podem ser utilizados sem modificar a eficiência do trator.

\section{LITERATURA CITADA}

ASAE-American Society of Agricultural Engineers, S296.4 DEC95 Uniform terminology for traction of agricultural tractors, selfpropelled implements, and other traction and transport devices. In: ASAE Standards: Standards engineering practices data. St. Joseph: American Society of Agricultural Engineers, 1999. p.119-121.

Barbosa, J. A.; Vieira, L. B.; Dias, G. P.; Dias Junior, M. S. Desempenho operacional de um trator equipado alternadamente com pneus radiais e diagonais. Engenharia Agrícola, v.25, p.474-480, 2005.

Cordeiro M. A. L. Desempenho de um trator agrícola em função do pneu, da lastragem e da velocidade de deslocamento. Botucatu: FCA/UNESP, 2000. 153p. Tese Doutorado

Correa, I. M.; Yanai, K.; Maziero, J. V. G.; Lanças, K. P. Determinação da circunferência de rolamento de pneus agrícolas utilizando dois métodos: Manual e eletrônico. Bragantia, v.58, n.1, p.179-184, 1999.

EMBRAPA - Empresa Brasileira de Pesquisa Agropecuária, Centro Nacional de Pesquisa de Solos. Sistema brasileiro de classificação de solos. Rio de Janeiro: Embrapa/CNPS, 1999. 412p.

Gabriel Filho, A; Lanças, K. P.; Leite, F.; Acosta, J. J. B.; Jesuino, P. R. Desempenho do trator agrícola em três superfícies de solo e quatro velocidades de deslocamento. Revista Brasileira de Engenharia Agrícola e Ambiental, v.14, n.3, p.333-339, 2010.

Gabriel Filho, A.; Silva, S. L.; Modolo, A. J.; Silveira, J. C. Desempenho de um trator operando em solo com diferentes tipos de cobertura vegetal. Engenharia Agrícola. v.24, n.3, p.781-789, 2004.

Kiehl, E. J. Manual de edafologia. São Paulo: CERES, 1979. 267p.

Mazetto, F. R.; Lanças, K. P.; Nagaoka, A. K.; Castro Neto, P.; Guerra, S. P. S.; Avaliação do contato pneu-solo em três modelos de pneus agrícolas. Engenharia Agrícola, v.24, n.3, p.750-757, 2004.

Salvador, N.; Mion, R. L.; Benez, S. H. Consumo de combustível em diferentes sistemas de preparo periódico realizados antes e depois da operação de subsolagem. Ciências e Agrotecnologia. v.33, n.3, p. 870-874, 2009.

Yanai, K.; Silveira, G. M.; Lanças, K. P.; Corrêa. I. M.; Maziero, J. V. G. Desempenho operacional de trator com e sem acionamento da tração dianteira auxiliar. Pesquisa Agropecuária Brasileira, v.34, n.8, p.1427-1434, 1999.

Zoz, F., Grisso, R.D. Traction and tractor performance. St Joseph: ASAE. 2003. 46p. 